\title{
Discontinuous Elastic Lamine In The Internal Iliac Artery in Lamb
}

\author{
Vasile RUS ${ }^{1}$, Flavia RUXANDA ${ }^{1}$, Cristian RAŢIU ${ }^{2}$, Adrian GAL ${ }^{1 *}$,Viorel MICLĂUŞ ${ }^{1}$ \\ ${ }^{1}$ University of Agricultural Sciences and Veterinary Medicine Cluj-Napoca, Romania \\ ${ }^{2}$ University of Oradea, Faculty of Medicine and Pharmacy, Oradea, Romania \\ *Corresponding author: adrianfloringal@yahoo.com \\ Bulletin UASVM Veterinary Medicine 72(2) / 2015, \\ Print ISSN 1843-5270; Electronic ISSN 1843-5378 \\ DOI:10.15835/buasvmcn-vm: 11372
}

\begin{abstract}
Fragments from three hybrid Merino lambs were harvested from the internal iliac arteries and processed in order to conduct histological investigations. Structurally, these arteries fall under the muscle arteries category. În one of the lambs we observed the absence of elastic laminae (internal and external) on a certain segment of the vessel cicumference. The absence of elastic laminae on a certain segment, only in one animal, does not seem to have a functional or pathological signification, thus we believe that we have intercepted the passage zone from transitional arteries to musclular ones.
\end{abstract}

Keywords: elastic lamina, iliac artery, lamb

\section{INTRODUCTION}

The cardiovascular apparatus is a closed system (Miclăuş, 2012), in which the blood pumped by the heart flows through arteries towards the capillary network and then back to the heart through veins. The internal iliac arteries originate in the abdominal descending aorta. They emerge alongside with external iliac and median sacral arteries when the aorta passes near the last lumbar vertebrae (Damian, 2010).

The arterial wall is formed out of intima, media and adventitia (Gal and Miclăuș, 2013). Depending on the structure of tunica media, arteries can be elastic or muscular (Aughey and Frye, 2001). The elastic fibers that form tunica media of the elastic arteries and the elastic lamine are organized as elastic lamellae (Gal and Miclăuş, 2009).

Tunica media in arteries is bordered by two elastic lamine. The internal elastic lamina comprises 2-3 elastic lamellae with a compact disposition. The external elasticlaminacontains 3-4 elastic lamellae, which are thinner in comparison to the ones in the internal elastic lamina and they usually have a less compact disposition (Miclăuş, 2012). In the case of some specialized arteries, for instance coronary arteries, the internal elastic lamina is disposed in the middle of tunica media (Raica et al., 2004).

\section{MATERIALS AND METHODS}

We harvested the internal iliac arteries from 3 male hybrid Merino lambs (approximately 3 months old), sacrificed by the breeders for own consumption. The samples had an approximately 4 $\mathrm{mm}$ thickness. They were fixed in Stieve's solution for 24 hours long, dehydrated in ethanol, clarified in n-butanol and embedded in paraffin. From the obtained blocks we made seriated sections with a $5 \mu \mathrm{m}$ thickness and mounted them on slides. The slides were subsequently stained with Goldner's trichrome method, as a usual staining, and Verhoeff method as an elective stain for elastic tissue. The histological specimens were examined with a light microscope (Olimpus BX 41) and images were captured (Olimpus E 330), which were digitally processed (Adobe Photoshop CS 2).

\section{RESULTS AND DICUSSION}

The internal iliac arteries can be categorized as muscular type of ateries considering the structure of their three tunicae (Fig. 1). In tunica media's 
structure, there is a small amount of connective tissue among the muscle cells, similar to other muscle arteries (Fig. 2). On Verhoeff stain, we can observe that there are some elastic fibers in the connective tissue from tunica media's structure. They are relatively fine and discontinuous (Fig. 3). In two of the lambs taken into study, tunica media is bordered by an internal elastic lamina towards its inner part, and an external elastic lamina towards the outer part. Both lamine have a typical structure.

In one of the lambs, the internal elastic lamina of the right internal iliac artery is discontinuous (Fig. 4), being absent on approximately $30-40 \%$ of the circumference of the wall. The external

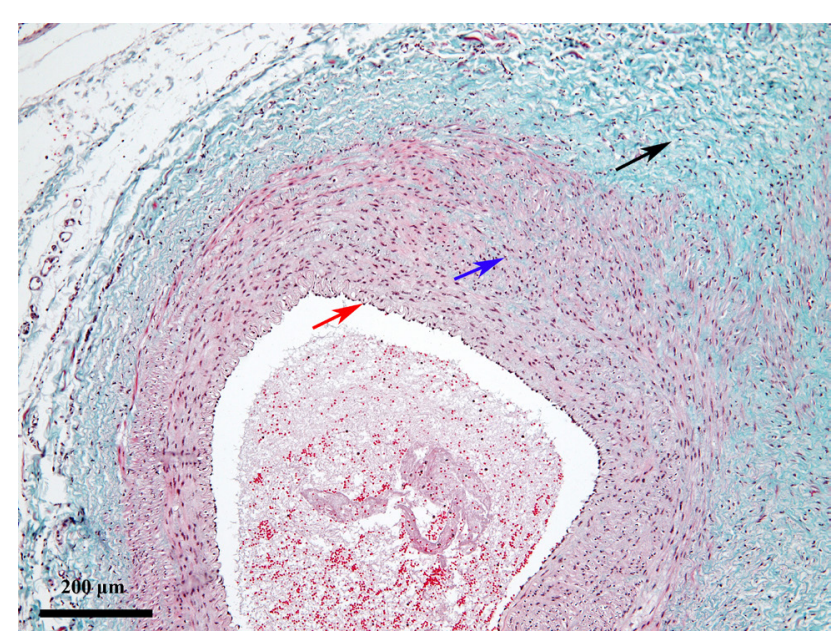

Fig. 1. Internal iliac artery - tunicae proportion: red arrow - intima; blue arrow - media; black arrow adventitia (Goldner's trichrome stain)

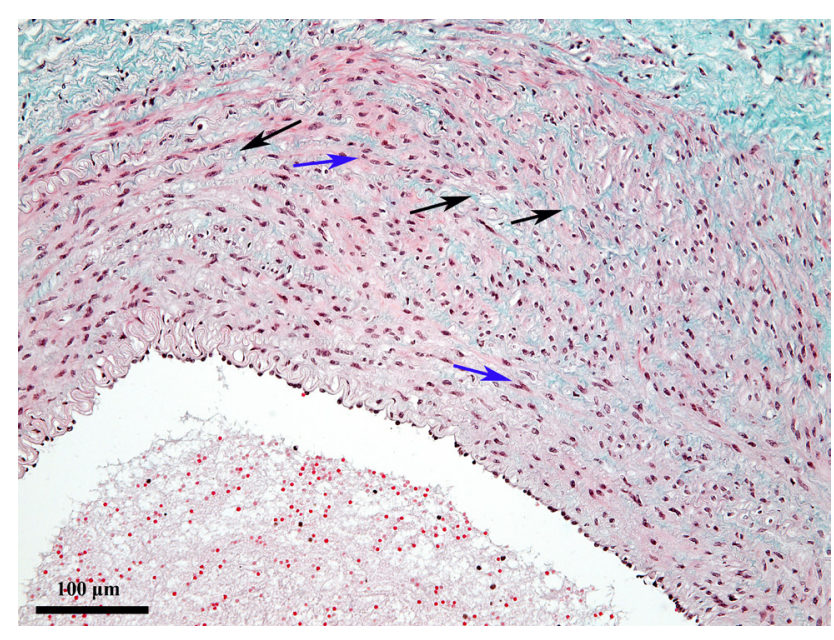

Fig. 2. Internal iliac artery - tunica media's structure: blue arrow - smooth muscle tissue; black arrow connective tissue (Goldner's trichrome stain) elastic lamina appears interrupted as well, on the same area as the internal one (Fig. 5). The absence of the external elastic limitant was noticed by Masuka et al. (2010) in the intracranian segment of the carotid artery. The authors claim that this aspect might lead to an decrease in the elasticity of the vessels, increasing the possiblity of atherosclerosis processes emergence. Also, in the case of the vertebral artery, the reduction or even disappearance of the elastic fibers in tunica media's structure and external elastic lamina (Fang, 1958; Wilkinson, 1972).

The results we obtained differ from those reported in the specialty literature. Thus, we

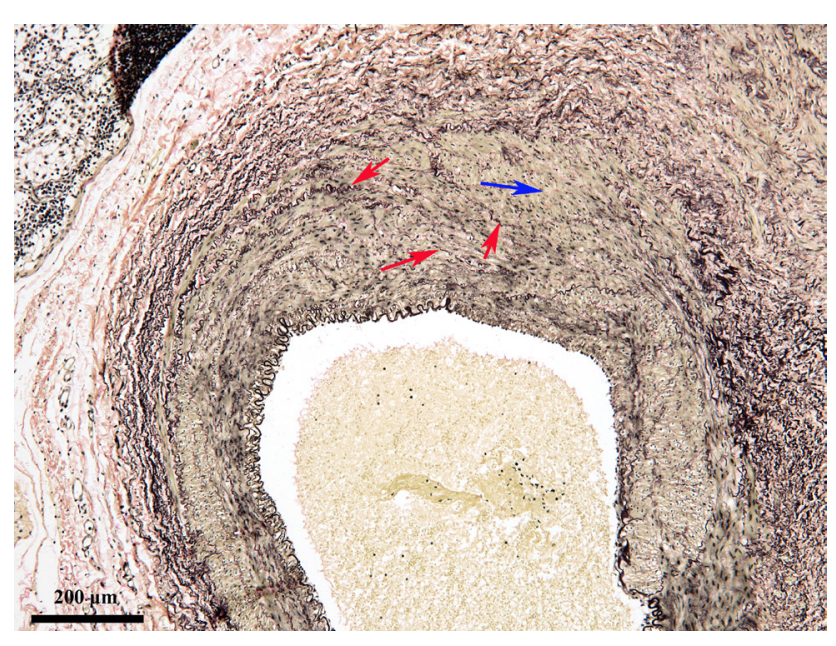

Fig. 3. Internal iliac artery - tunica media's structure: blue arrow - muscule tissue; red arrow - elastic fibers (Verhoeff stain)

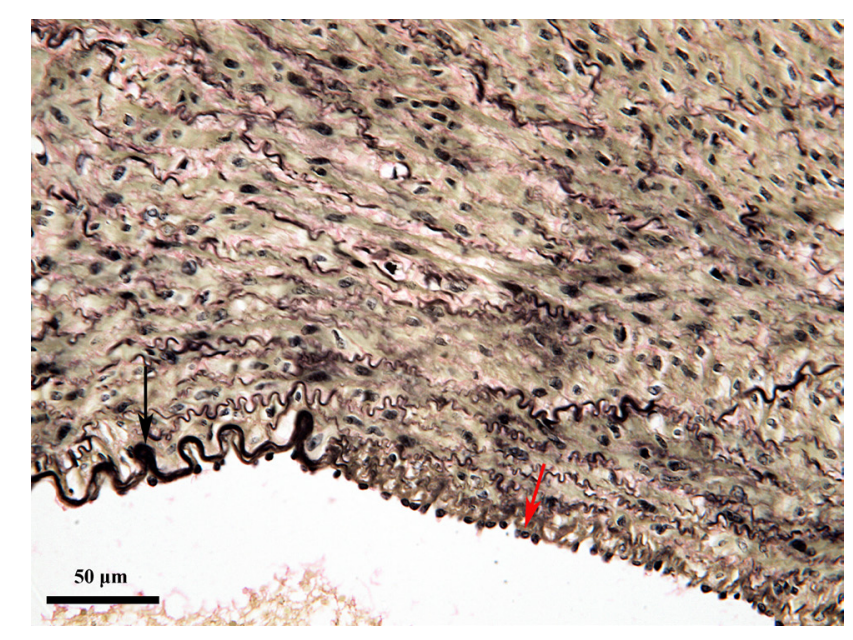

Fig. 4. Internal iliac artery: internal elastic lamina - black arrow; absence of the lamina - red arrow (Verhoeff stain) 


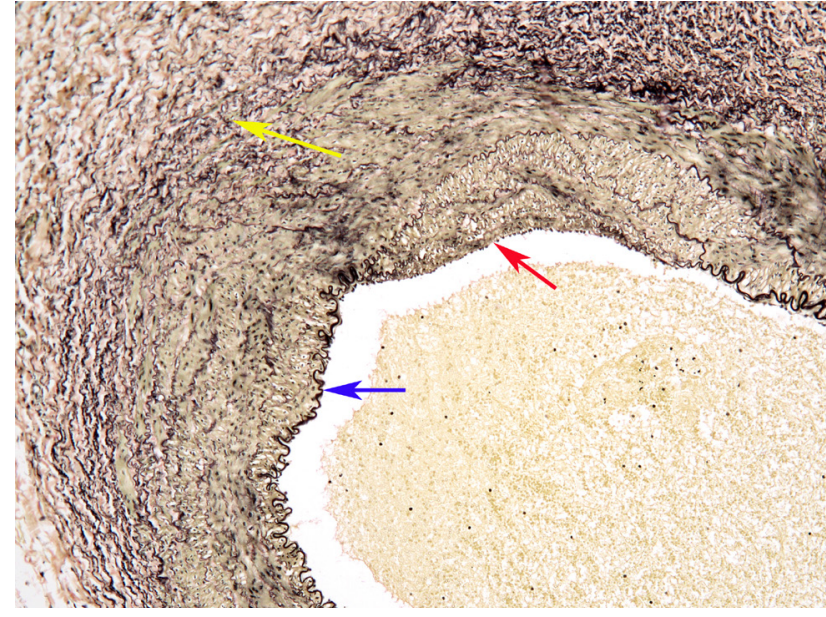

Fig. 5. Internal iliac artery: internal elastic lamina blue arrow; absence of internal elastic lamina - red arrow; white arrow -external elastic lamina; yellow arrow - absence of external elastic lamina (Verhoeff stain)

observed the partial absence of both internal and external elastic laminae only on a certain segment of the vessel circumference and only in one artery in one animal. In the case of the intracranial segment of the internal carotid and vertebral arteries in man, the absence of the whole external elastic lamina is signaled. The authors sustain that the external elastic lamina is absent in all individuals.

The absence of external elastic lamina in the mentioned arterial segments seems to be a structural adaptation to the internal and external pressure that exerts on these central nervous system vessels. These vessels are categorized as specialized arteries.

In the case of the internal iliac arteries, the circulation pattern markedly differs from the one in the nervous system, the blood pressure being significantly higher here. Thus, the absence of the elastic laminae in one animal and only one of the internal iliac arteries (right internal iliac artery) suggests the fact that this aspect is not a characteristic of these arteries, but an aspect linked to the transition from one type of artery to another. In other words, we consider that we have intercepted the passage zone from arteries, with less delineated internal elastic laminae, to musclular ones, in which the laminae are well represented, constant and continuous.

\section{CONCLUSION}

The internal iliac arteries in lamb fall under the typical muscle arteries, in which tunica media is muscular and bordered by well represented, continuous internal and external elastic laminae. The right iliac arteries in one of the lambs contained elastic laminae present on only two thirds of the vessel circumference. We consider that the aspect can not have a functional signification, therefore we believe that we intercepted the passage zone between the transition and muscular arteries.

\section{REFERENCES}

1. Aughey E, Frye F L (2001). Comparative Veterinary Histology with Clinical Correlates. Iowa State University Press, 71-81

2. Damian A (2010). Anatomie Comparată, sistemul cardiovascular. AcademincPres,Cluj- Napoca , 102-103.

3. Fang H (1958). A comparison of blood vessels of brain and peripheral blood vessels. In: Wright IS, Millikan CH. Cerebral Vascular Diseases, Grune \& Stratton, New York, 17-22.

4. Gal A F, Miclăuș V (2009). Cell biology and general histology. AcademicPres,Cluj-Napoca, 165-166.

5. Gal A F, Miclăuș V (2013). Histology. Risoprint, ClujNapoca, 165-180.

6. Masuoka T, Hayashi N, Hori E, Kuwayama N, Ohtani 0, Endo S (2010). Distribution of internal elastic lamina and external elastic lamina in the internal carotid artery: possible relationship with atherosclerosis. Neurol Med Chir (Tokyo) 50(3):179-82.

7. Miclăuș V (2012). Histologie specială și embiologie generală. Ed a II-a, Risoprint, Cluj-Napoca, 7-22.

8. Raica M, Mederle O, Caruntu ID, Pintea A, Chindris AM (2004). Histologie teoretică și practică. Brumar, Timișoara, 101-120.

9. Wilkinson IMS (1972). The vertebral artery. Extracranial and intra-cranial structure. Arch Neurol 27:392-396. 